\title{
ANALISA KADAR TIMBAL PADA SAYUR KUBIS (Brassica oleracea L.var. capitata L) YANG DITANAM DI PINGGIR JALAN TANAH KARO BERASTAGI
}

\author{
Sri Bulan Nasution \\ Analis Kesehatan Kemenkes Medan
}

\begin{abstract}
Abstrak
Kubis (Brassica oleracea L.var capitata $L$ ) merupakan sumber vitamin serta mineral dan terkandung beberapa macam vitamin yang sangat penting untuk memenuhi nutrisi kita. Kubis cukup banyak mengandung vitamin $\mathrm{C}$ bila dibandingkan dengan sayuran yang lain. Penelitian Kadar Timbal ( $\mathrm{Pb}$ ) pada sayur Kubis dilakukan di Laboratorium Kimia Politeknik Kesehatan Kemenkes RI Medan Jurusan Analis Kesehatan dan Balai Laboratorium Kesehatan Medan pada Bulan Maret - juli 2013. Tujuan penelitian ini untuk mengetahui kadar Timbal $(\mathrm{Pb})$ pada sayur kubis. Sampel diambil Dipinggir Jalan Tanah Karo Berastagi sebanyak 5 sampel sayur kubis secara acak. Pemeriksaan Kadar Timbal pada Sayur Kubis dilakukan dengan Metode Spektrofotometer Serapan Atom (SSA) panjang gelombang 248,3 nm dengan sampel berjumlah 5 sayur Kubis. Hasil uji kuantitatif diperoleh kadar Timbal pada Sayur Kubis berkisar 0,25 mg\% - 0,55 mg\%. Sedangkan batas maksimum Timbal pada sayuran menurut SNI sebanyak 0,5. Dan dari hasil tersebut menunjukkan dimana Kadar Timbal $(\mathrm{Pb})$ pada Sampel 2 melebihi dari batas maksimum.
\end{abstract}

Kata Kunci : Kubis, Kadar Timbal (Pb), Spektrofotometer Serapan Atom

\section{LATAR BELAKANG}

Kubis adalah tanaman yang termasuk dalam famili Cruciferae dan mempunyai nama latin Brassica oleracea. Tanaman ini merupakan salah satu jenis tanaman sayur yang umum diusahakan oleh para petani Indonesia. Di dalam kubis terkandung beberapa macam vitamin yang sangat penting untuk memenuhi kebutuhan nutrisi kita, misalnya vitamin A 200 IU, vitamin B 20 IU, dan vitamin C 120 IU. Kubis terdiri dari beberapa jenis, yaitu kubis krop (Brassica Oleracea L. Var. Cagitata L.), kubis ini memiliki daun yang membentuk telur (krop). Warna daunnya yang putih, maka disebut juga dengan kubis putih atau kubis. (Tafajani, 2011)

Penanaman dipinggir jalan sangat berbahaya untuk di konsumsi karena dapat mempengaruhi keamanan sayuran. Pangan yang dikonsumsi sehari-hari merupakan hasil pertanian. Pangan seharusnya memenuhi kriteria ASUH (Aman, sehat, utuh, dan halal). salah satu parameter tersebut, yaitu Aman, termasuk dalam masalah mutu. Mutu dan keamanan pangan berpengaruh langsung terhadap kesehatan masyarakat dan perkembangan sosial. Makanan yang bermutu baik dan aman diperlukan untuk meningkatkan kesehatan, kesejahteraan individu dan kemakmuran masyarakat. Sayuran merupakan sumber pangan yang mengandung banyak vitamin dan mineral yang secara langsung berperan meningkatkan kesehatan. Oleh karna itu, higienitas dan keamanan sayuran yang dikonsumsi menjadi sangat penting agar tidak menimbulkan gangguan kesehatan. Namun banyak jenis sayuran yang beredar dimasyarakat tidak terjamin keamanannya karena diduga telah terkontaminasi logam- logam berat seperti timbal. (Suismono, Widraningrum, 2007)

Timbal atau dalam keseharian lebih dikenal dengan nama timah hitam. dalam bahasa ilmiahnya dinamakan plumbum, dan logam ini disimbolkan dengan $\mathrm{Pb}$. Logam ini termasuk kedalam kelompok logam-logam golongan IV-A pada Tabel periodik unsur kimia. Mempunyai nomor atom (NA) 82 dengan bobot atau berat atom (BA) 207,2.

Jumlah $\mathrm{Pb}$ di udara mengalami peningkatan yang sangat drastis sejak dimulainya revolusi industri di Benua Eropa. Asap yang berasal dari cerobongan pabrik sampai pada knalpot kendaraan telah melepaskan Pb ke udara. Hal ini berlangsung terus-menerus sepanjang hari, sehingga kandungan $\mathrm{Pb}$ di udara naik secara sangat mencolok sekali. Kenyataan ini secara dramatis dibuktikan dengan suatu hasil penelitian terhadap kandungan $\mathrm{Pb}$ yang terdapat pada lapisan es di Greenland pada tahun 1969. ( Palar, 2008).

Biasanya kadar $\mathrm{Pb}$ dalam tanah berkisar antara 5$25 \mathrm{mg} / \mathrm{k}$, dalam air tanah dari 1-60 $\mu \mathrm{g} / \mathrm{I}$ dan agak lebih rendah dalam air permukaan di alam; kadar di udara di bawah $1 \mu \mathrm{g} / \mathrm{m}^{3}$, tetapi dapat jauh lebih tinggi di tempat kerja tertentu dan di daerah yang lalu-lintasnya padat. (Frank, 2002).

Tanah mungkin mengandung komponen $\mathrm{Pb}$ arsenat yang stabil karena komponen ini banyak digunakan sebagai pestisida sebelum perang dunia kedua. Tetapi pada saat ini pestida tersebut tidak digunakan lagi karena telah banyak diganti dengan pestisida organik. Di daerah-daerah pertanian yang dekat dengan jalan-jalan raya pada umumnya kandungan $\mathrm{Pb}$ pada hasil-hasil pertaniannya lebih tinggi dibandingkan dengan hasil-hasil pertanian 
yang dipanen dari daerah-daerah yang jauh dari jalan raya. Hal ini menunjukkan bahwa pencemaran $\mathrm{Pb}$ umumnya berasal dari kendaraan-kendaraan bermotor. ( Fardiaz, 2006)

Keracunan yang ditimbulkan oleh persenyawaan logam $\mathrm{Pb}$ dapat terjadi karena masuknya persenyawaan logam tersebut ke dalam tubuh. Proses masuknya $\mathrm{Pb}$ ke dalam tubuh dapat melalui beberapa jalur, yaitu melalui makanan dan minuman, udara dan perembesan atau penetrasi pada selaput atau lapisan kulit. ( Palar, 2008)

Susunan saraf juga merupakan organ sasaran utama $\mathrm{Pb}$. setelah tingkat pajanan tinggi, dengan kadar $\mathrm{Pb}$ darah di atas $80 \mu \mathrm{g} / \mathrm{dl}$, dapat terjadi ensefalopati. Terjadi kerusakan pada arteriol dan kapiler yang mengakibatkan edema otak, meningkatnya tekanan cairan serebrospial, degenerasi neuron, dan perkembangbiakan sel glia. Secara klinis keadaan ini disertai dengan munculnya ataksia, stupor, koma, dan kejang-kejang. (Frank, 2002)

Dalam waktu dua hari yaitu pada hari sabtu dan minggu kendaraan roda dua yang lewat dari pukul 09.0015.00 mencapai sebanyak 550 kendaraan,dan kendaraan roda 4 yang lewat dari pukul 09.00-15.00 mencapai 600 kendaraan.

\section{A. Mengenal Tanaman Kubis}

Berdasarkan tata nama botani, tanama kubis diklasifikasikan ke dalam:

$\begin{array}{ll}\text { Diviso } & \text { : Spermatophyta } \\ \text { Sub diviso } & \text { : Angiospermae } \\ \text { Kelas } & \text { : Dicotyledonae } \\ \text { Ordo } & \text { : Papavorales } \\ \text { Famili } & \text { : Cruciferae (Brassicaceae) } \\ \text { Genus } & \text { : Brassica }\end{array}$

Spesies : Brassica oleraceae L. var. capitata L. (Rukmana, 2002)

Mula-mula kubis banyak terdapat dalam keadaan liar di sepanjang pantai laut Tengah, demikian juga di karang-karang dipantai inggris, Denmark, dan pantai barat perancis sebelah utara.

Kubis telah dikenal sejak zaman purbakala pada tahun 2500-2000 sebelum Masehi, dan tanaman tersebut sangat dipuja dan dimuliakan oleh orang mesir dan Yunani Kuna. Tanaman kubis mulai ditanam di kebun-kebun di Eropa kira-kira pada abad ke 9 dan di Amerika pada waktu permulaan pada emigran Eropa menetap. Ditanam di indonesia mungkin pada waktu orang Eropa mulai berdagang dan menetap di indonesia pada abad ke 16 atau 17.

Pada waktu Eropa mengelilingi dunia dengan naik kapal banyak yang menderita sariawan, tetapi setelah mereka membawa buah-buahan dan sayuran di antaranya kubis, mereka tidak lagi diserang penyakit sariawan, karena sayuran tersebut cukup banyak mengandung vitamin C. Tapi karena kubis tidak dapat disimpan dalam waktu yang lama, mereka mulai menanamnya di tempat mereka mulai menetap dalam waktu yang lama. (Pracaya, 2000).

Bila berjalan-jalan di pegunungan yang tinggi, misalnya di Lembang dan Cianjur (Jawa Barat), atau ke Wonosobo (Jawa Tengah), Malang (Jawa Timur),
Berastagi (Sumatera Utara), banyak dijumpai kebun kubis. Kubis atau kol umumnya tumbuh di dataran tinggi. Sosok tanaman ini pendek-pendek. Bunganya berwarna kuning. Bunga kubis ini akan dapat muncul bila lingkungannya dalam 1 bulan bersuhu 5-10 ${ }^{\circ} \mathrm{C}$. (Duryatmo, 2006).

\section{B. Kandungan Gizi}

Kubis termasuk salah satu sayuran daun yang digemari oleh hampir setiap orang. Cita rasanya enak dan lezat, juga mengandung gizi cukup tinggi serta komposisinya lengkap, baik vitamin maupun mineral. Kandungan gizi kubis 100 gram bahan segar seperti :Kalori 25,0 kal, Protein 1,7 gr, Lemak 0,2 gr, Karbohidrat 5,3 gr, Kalsium 64,0 mg, Fosfor 26,0 mg, Zat Besi 0,7 mg, Natrium 8,0 mg, Niacin 0,3 mg, Serat 0,9 gr, Abu 0,7 gr. (Direktorat Gizi Depkes R.I. 1981 dan Food \& Nutrition Research Center, Manila 1964).

\section{Syarat Tumbuh}

a. Iklim

Kubis dapat tumbuh di dataran tinggi (1000-2000 $\mathrm{m}$ dpl) untuk varietas dataran tinggi dan di dataran rendah (100-200 m dpl) untuk varietas dataran rendah. Suhu udara 15-20 ${ }^{\circ} \mathrm{C}$ dengan kelembapan 80-90 \%. Pertumbuhan kubis paling baik di daerah yang hawanya dingin. Bila temperature turun sampai dibawah $-10^{\circ} \mathrm{C}$ dan tetap bertahan untuk waktu yang lama akibatnya tanaman menjadi sangat rusak. Kubis dapat bertahan pada temperature rendah apabila penurunan berlangsung dengan perlahan-lahan dan tanaman dalam keadaan setengah tumbuh. Tanaman muda mempunyai daerah temperature pertumbuhan yang lebih lebar dari pada tanaman yang tua. b. Tanah

Tanah yang dikehendaki tanaman kubis, yaitu tanah subur, gembur, dan banyak mengandung humus dengan ph berkisar 6,0-7,0. Kubis tidak dapat tumbuh baik di tanah yang sangat asam. Apabila ditanam pada ph 4,3 hasilnya sangat akan berkurang, tetapi apabila ph dinaikkan sampai 6,0 hasil akan meningkat cukup banyak. Pada ph antara 5,5 dan 6,5, phosphor masih dapat tersedia untuk tanaman. Untuk menaikkan ph dapat diberi kapur mati Ca $(\mathrm{OH}) 2$ dan jangan melebihi ph 6,5. Kecuali kalau ada serangan penyakit akar membengkak (clubroot) yang serius ph perlu dinaikkan sampai netral atau alkalis. (Rukmana, 2002)

c. Sinar Matahari

Tanaman kubis memerlukan sinar matahari yang cukup. Apabila ditanam di tempat yang kurang mendapat sinar matahari, pertumbuhannya kurang baik, mudah terserang penyakit, pada waktu kecil terjadi pertumbuhan etiolasi.

d. Air

Di daerah yang cukup sinar dan temperature yang cocok untuk pertumbuhan tanaman kubis dapat ditanam sepanjang tahun, Asal pada waktu musim hujan air tak tergenang dan pada waktu musim kemarau masih tersedia cukup air. (Pracaya, 2000) 


\section{Persemaian dan Pembibitan}

Sebelum penanaman, bibit disemaikan dulu di tempat pembibitan. Ada 2 cara persemaian, Yaitu:

a. Persemaian di atas bedengan

- $\quad$ Buat bedengan dengan lebar 1-1,2 m, panjang berdasarkan kebutuhan, dan tinggi $\pm 20 \mathrm{~cm}$. Kemudian, tebarkan pupuk kandang $\pm 1 \mathrm{~kg} / \mathrm{m}^{2}$ ditambah NPK 85 gram $/ \mathrm{m}^{2}$ yang dicampur dengan tanah dan dihaluskan.

- Sebar benih secara merata kemudian tutup dengan tanah halus tipis-tipis dan siram bedengan dengan hati-hati.

- Buat atap untuk menaungi persemaian, tinggi sebelah timur 1,5 m dan sebelah barat $75 \mathrm{~cm}$.

- $\quad$ Pelihara bibit tersebut sampai berdaun 4 dan bibit siap dipindah ke lahan dengan cara dicabut.

b. Persemaian dalam polybag pembibitan

- Siapkan polybag pembibitan ukuran 6 × $8 \mathrm{~cm}$ atau $8 \times 10 \mathrm{~cm}$. Isi polybag dengan media tanah. Campuran tanah, pasir, dan pupuk kandang dengan perbandingan 1 : 1 :1 ditambah NPK sebanyak 85 g/1 ember (isi 10 liter air).

- Basahi media tersebut kemudian masukkan benih kubis, 1 benih/polybag dan disiram. Atur polybag tersebut dengan bedengan-bedengan yang lebarnya 1-1,2 m dan panjang sesuai kebutuhan.

- Buat naungan seperti pada persemaian di atas bedengan.

- $\quad$ Pelihara bibit tersebut sampai berdaun 4 dan bibit siap dipindah ke lahan.(Siswandi, 2006)

Selama di persemaian dilakukan pemeliharaan bibit sebaik mungkin, terutama penyiraman dan pemupukan dengan ZA 30 gram atau Urea 15 gram dalam 9-10 liter air diikuti penyiraman air bersih, serta penyemprotan pestisida pada konsentrasi rendah (setengah dosis) bila ada serangan hama dan penyakit. Pemupukan ini dilakukan pada waktu bibit kubis berumur 1 minggu setelah penyapihan. Bibit kubis siap dipindah tanamkan ke kebun apabila sudah berdaun \pm 4 helai.

c. Penyiapan Lahan (Pengolahan Tanah)

Bersamaan dengan kegiatan pembibitan di persemaian, lahan untuk kebun kubis segera diolah. Tahapan pengolahan tanah untuk bertanam kubis adalah sebagai berikut:

- Buang rumput-rumput liar (gulma) ataupun batu kerikil dari sekitar kebun.

- Olah tanah dengan cangkul atau bajak sedalam \pm 30 - $40 \mathrm{~cm}$ hingga menjadi gembur, kemudian dibuat pula parit kelilingnya selebar $40-60 \mathrm{~cm}$.

- Buat lubang tanam ukuran 30 × 30 × 30 c atau 40 x 40 x $40 \mathrm{~cm}$ pada jarak $60 \mathrm{~cm}$ x $50 \mathrm{~cm}$. Kemudian tiap lubang tanam diisi pupuk kandang yang telah matang sebanyak $0,5-1,0 \mathrm{~kg}$ atau dosis per hektarnya antara 15 - 20 ton. Pupuk kandang ini dapat pula diberikan dengan cara dicampur merata dengan tanah pada saat membuat bedengan. (Rukmana, 2002)

\section{E. Fase Tanam}

\section{a. Proses fase tanam}

- Jarak tanam: jarak tanam jarang 70x50 cm atau jarak tanam rapat $60 \times 5 \mathrm{~cm}$.

- Bibit: Bibit yang telah berumur 3-4 minggu memiliki 4-5 daun siap tanam.

- Pemupukan: Pupuk dasar diberikan sehari sebelum tanam dengan dosis anjuran setempat (kalau menggunakan paket BioFOB maka dianjurkan menggurangi 25-50\%). Pupuk dasar dicampur secara merata, lalu diberikan pada lubang tanam yang telah diberikan pupuk Organo TRIBA, lalu ditutupi dengan tanah.

\section{b. Cara Tanam}

- Buat lubang tanam dengan tunggal sesuai jarak tanam. Pilih bibit yang segar dan sehat. Tanam bibit pada lubang tanam.

- Bila bibit disemai pada bumbung daun pisang langsung ditanam bersama bumbungnya.

- Bila bibit disemai pada polybag plastik, keluarkan bibit dari polybag lalu baru ditanam.

- Bila disemai dalam bedengan ambil bibit beserta tanahnya sekitar 2-3 cm dari batang sedalam $5 \mathrm{~cm}$ dengan solet (sistem putaran).

- Setelah ditanam, siram bibit air dengan air sampah basah. Kubis dapat ditumpang sarikan dengan tomat dengan cara tanam : 2 baris kubis 1 baris tomat. Tomat ditanam 3 atau 4 minggu sebelum kubis. (Tombe, 2010)

Tahap selanjutnya adalah pemeliharaan tanaman yang meliputi beberapa kegiatan pokok, yaitu:

1. Penyiraman (Pengairan)

- Dilakukan dengan cara dileb atau disiram,tergantung kepraktisan fasilitas yang ada.

- Pada fase awal pertumbuhan dan keadaan tanah yang kering, pengairan dilakukan 1-2 hari sekali. Pengairan selanjutnya dikurangi, tetapi tanah tidak boleh kekeringan.

2. Penyiangan (pendangiran)

- Selama musim pertanaman kubis minimal dilakukan penyiangan 2 kali bersamaan dengan kegiatan penggemburan tanah dan pemupukan, yaitu pada umur 2 dan 4 minggu setelah tanam.

- Penyiangan harus dilakukan dengan hati-hati dengan alat bantu kored atau pun cangkul, agar tidak merusak perakaran.

- Sambil menyiang, tanah dari parit dinaikkan kebedengan agar aerasi dan drainase tanahnya baik. (Rukmana, 2002).

\section{F. Pemupukan}

- Pemupukan dilakukan pada saat tanaman berumur 2 minggu dan diulang pada umur 4 minggu setelah tanam.

- Jenis dan dosis pupuk yang digunakan terdiri atas N,P,dan K atau campuran urea $250 \mathrm{~kg}$ atau setara dengan ZA 500kg/ha,TSP 200kg/ha,dan ZK atau $\mathrm{KCl} 200 \mathrm{~kg} / \mathrm{ha}$. Pupuk TSP dan $\mathrm{KCl}$ atau ZK diberikan seluruh dosis pada waktu pemupukan 
pertama (umur 2 minggu setelah tanam) ditambah pupuk urea atau ZA setengah dosis. Sisa pupuk nitrogen setengah dosis lagi diberikan pada waktu tanaman berumur 4 minggu setelah tanam. Tiap tanaman kubis dipupuk sekitar 10-20 gram pupuk campuran setiap kali pemupukan.

- Tata cara pemberian pupuk yaitu mula-mula dibuat alur pupuk diatas bedengan sedalam $5 \mathrm{~cm}$ secara melingkar di sekeliling tanaman sejauh 10-15 cm atau disesuaikan dengan lebar mahkota daun. Dapat pula diatur mengikuti barisan tanaman, tetapi pada pemupukan susulan sebaiknya dalam larikan yang berbeda (arah memotong barisan tanaman). Berikutnya masukan pupuk secara hati-hati ke dalam alur-alur, kemudian tutup dengan tanah. Bila keadaan tanahnya kering, perlu diikuti dengan penyiraman (pengarian). (Rukmana, 2002)

\section{G. Pengendalian Hama dan Penyakit \\ 1.Hama}

- Ulat tritip (Plutella xyloslella, L)

Merupakan hama utama tanaman kubis, serangannya dapat menyebabakan kehilangan hasil antara 58-100\%, terutama di musim kemarau. Ulat berwarna hijau, panjang 8-10 mm. Gejala serangan, daun berlubang-lubang, jika serangan hebat hanya menyisatkan urat daun.

- Ulat titik tumbuh (Crocidolomia binotalis)

Ulat berwarna hijau, panjang $18 \mathrm{~mm}$, pada punggung terdapat garis berwarna hijau muda. Gejala serangan, bagian titik tumbuh tanaman rusak.

Pengendalian dilakukan dengan cara mekanis, yaitu dengan mencari ulat kemudian dibunuh. Pemanfaatan musuh alami, misalnya Cotesia plutella dan penggunaan insektisida.

2.Penyakit

- Busuk hitam

Penyebab penyakit bakteri Xanthomonas Campestris. Gejala serangan, mula-mula tepi daun berwarna kuning atau pucat kemudian meluas ke bagian tengah. Urat-urat daun hingga batang tampak hitam.

- Bercak daun

Penyebab penyakit cendawan Alternaria brassicae. Gejala serangan, daun berbintik-bintik kelabu kemudian menjadi bercak cokelat.

Pengendalian:

Sebelum disemai, benih direndam dalam larutan sublimat $1 \%$ selama 15 menit,pergiliran tanaman,dan penggunaan fungisida atau bakterisida.

\section{H. Panen}

\section{Umur panen}

Kubis dipanen pada umur 3-4 bulan setelah semai atau 2-3 bulan setelah pindah tanam, tergantung varietas. Selain umur, tanda kubis siap panen tampak pada krop yang telah mencapai ukuran maksimal, padat, dan kompak.
2. Cara panen

Tata cara panen kubis adalah mula-mula mematahkan daun-daun tua disebelah bawah krop; kemudian krop dipotong tepat di bagian bawahnya dengan alat bantu pisau yang tajam. Daun yang tua dan rusak dibersihkan, kemudian krop dimasukkan ke dalam keranjang untuk diangkut ketempat pengumpulan. Pada tanaman kubis yang dipelihara dengan baik (intensif) serta tidak mendapat serangan hama dan penyakit yang fatal, hasil panen dapat mencapai antara 20-40 ton/hektar, tergantung dari varietasnya. (Siswandi, 2006)

\section{Kebun Sayur Dipinggir Jalan Berbahaya}

Logam berat dapat terakumulasi dalam jumlah yang cukup besar dengan penanaman dipinggir jalan seperti padi, rumput, beberapa jenis leguminosa untuk pakan ternak, dan sayuran. Manusia bukan hanya menderita sakit karena menghirup udara yang tercemar, tetapi juga akibat mengasup makanan yang tercemar logam berat. Sumbernya sayur-sayuran dan buah-buahan yang ditanam di lingkungan yang tercemar atau daging dari ternak yang makan rumput yang sudah mengandung logam berat yang sangat berbahaya bagi kesehatan manusia. Usaha-usaha untuk menanggulangi pencemaran logam berat di Indonesia sampai saat ini belum banyak dilakukan.

Hal ini terutama karena sebagian besar industri di Indonesia belum mempunyai sarana pengolahan limbah yang memadai. Usaha yang dapat kita lakukan untuk menghindari bahaya logam berat, antara lain dengan menghindari penanaman dipinggir jalan dan sumber bahan pangan yang memiliki risiko mengandung logam berat, mencuci dan mengolah bahan pangan yang akan dikonsumsi dengan baik dan benar. Selain itu, kita juga perlu memperhatikan dan peduli terhadap lingkungan agar pencemaran tidak semakin bertambah jumlahnya. Peningkatan pengetahuan mengenai logam berat juga dapat bermanfaat dan membuat kita lebih waspada terhadap pencemaran logam berat.

Logam berat di dalam bahan pangan ternyata tidak hanya terdapat secara alami, namun juga dapat merupakan hasil migrasi dari bahan pengemasnya. Oleh karena itu, pengemasan bahan pangan harus dilakukan secara hatihati. Manusia bukan hanya menderita sakit karena menghirup udara yang tercemar, tetapi juga akibat mengasup makanan yang tercemar logam berat. Sumbernya sayur-sayuran dan buah-buahan yang ditanam di lingkungan yang tercemar atau daging dari ternak yang makan rumput yang sudah mengandung logam berat yang sangat berbahaya bagi kesehatan manusia. Usaha-usaha untuk menanggulangi pencemaran logam berat di Indonesia sampai saat ini belum banyak dilakukan. Hal ini terutama karena sebagian besar industri di Indonesia belum mempunyai sarana pengolahan limbah yang memadai.

Usaha yang dapat kita lakukan untuk menghindari bahaya logam berat, antara lain dengan menghindari sumber bahan pangan yang memiliki risiko mengandung logam berat, mencuci dan mengolah bahan yang akan dikonsumsi. Selain itu, kita juga perlu memperhatikan dan peduli terhadap lingkungan agar pencemaran tidak 
semakin bertambah jumlahnya. Peningkatan pengetahuan mengenai logam berat juga dapat bermanfaat bagi masyarakat.

Logam berat di dalam bahan pangan ternyata tidak hanya terdapat secara alami, namun juga dapat merupakan hasil migrasi dari bahan pengemasnya. Oleh karena itu, pengemasan bahan pangan harus dilakukan secara hatihati.

(http://anekaplanta.wordpress.com/2010/01/25/kebunsayur-di-pinggir-jalan-berbahaya/)

\section{J. Timbal}

Timbal atau dalam keseharian lebih dikenal dengan nama timah hitam. dalam bahasa ilmiahnya dinamakan Plumbum dan logam ini disimbolkan dengan $\mathrm{Pb}$. Logam ini termasuk kedalam logam kelompok logam-logam golongan IV-A pada Tabel Periodik unsur kimia. Mempunyai nomor atom (NA) 82 dengan bobot atau berat atom (BA) 207,2.

Dalam perkembangan industri kimia, dikenal pula aditive yang dapat ditambahkan ke dalam bahan bakar kendaraan bermotor persenyawaan yang dibentuk dari logam $\mathrm{Pb}$ sebagai aditive ini ada 2 jenis yaitu (CH3)4.Pb (tetrametil-Pb) dan $\left(\mathrm{C}_{2} \mathrm{H}_{5}\right) 4-\mathrm{Pb}$ (tetraetil-Pb). Bentukbentuk dari persenyawaan yang dibentuk oleh $\mathrm{Pb}$ dengan unsur kimia lainny, serta fungsi dari bentuk persenyawaan dapat dilihat sebagai berikut: Tetrametil-Pb dan Tetraetil$\mathrm{Pb}$ kegunaan sebagai Aditive untuk bahan bakar kendaraan bermotor. (Palar 2008)

\section{K. Sumber Polusi Timbal}

Gas timbal terutama berasal dari pembakaran bahan aditif bensin dari kendaraan bermotor yang terdiri dari tetraetil $\mathrm{Pb}$ dan tetrametil $\mathrm{Pb}$. Komponen-komponen $\mathrm{Pb}$ yang mengandung halogen terbentuk selama pembakaran bensin karena ke dalam bensin sering ditambahkan cairan antiletupan yang mengandung scavenger kimia. Bahan antiletupan yang aktif terdiri dari tetraetil $\mathrm{Pb}$ atau $\mathrm{Pb}\left(\mathrm{C}_{2} \mathrm{H}_{5}\right)_{4}$, Tetraetil $\mathrm{Pb}$ atau $\mathrm{Pb}\left(\mathrm{CH}_{3}\right)_{4}$, atau kombinasi dari keduanya. Scavenger ditambahkan supaya dapat bereaksi dengan komponen $\mathrm{Pb}$ yang tertinggal di dalam mesin sebagai akibat pembakaran bahan antiletupan tersebut. Komponen-komponen $\mathrm{Pb}$ yang dapat merusak mesin jika tertinggal, bereaksi dengan scavenger dan membentuk gas pada suhu tertentu saat mesin dijalankan, sehingga akan keluar bersama dengan bahan-bahan lainnyadan tidak akan merusak mesin. Dua macam scavenger yang sering digunakan adalah etilen dibromide $\left(\mathrm{C}_{2} \mathrm{H}_{4} \mathrm{Br}_{2}\right)$ dan etilen dikhloride $\left(\mathrm{C}_{2} \mathrm{H}_{4} \mathrm{CI}_{2}\right)$. Bahan aditif yang ditambahkan ke dalam bensin terdiri dari $62 \%$ tetraetil $\mathrm{Pb}, 18 \%$ etilen dibromide, $18 \%$ etilen dikhloride, dan $2 \%$ bahan-bahan lainnya.

Public Health Service di Amerika Serikat menetapkan bahwa sumber-sumber air alami untuk masyarakat tidak boleh mengandung $\mathrm{Pb}$ lebih dari 0.05 $\mathrm{mg} / \mathrm{I}(0.05 \mathrm{ppm})$, sedangkan WHO menetapkan batas $\mathrm{Pb}$ di dalam air sebesar $0.1 \mathrm{mg} / \mathrm{I}$.

Semua bahan pangan alami mengandung $\mathrm{Pb}$ dalam konsentrasi kecil, dan selama persiapan makanan mungkin kandungan $\mathrm{Pb}$ akan bertambah. Makanan- makanan asam dapat melarutkan $\mathrm{Pb}$ dari peralatan masak, alat-alat makan, dan wadah-wadah penyimpanan yang terbuat dari alloy $\mathrm{Pb}$ atau keramik yang dilapisi glaze.

Di daerah-daerah pertanian yang dekat dengan jalan-jalan raya pada umumnya kandungan $\mathrm{Pb}$ pada hasilhasil pertaniannya lebih tinggi dibandingkan dengan hasilhasil pertanian yang dipanen dari daerah-daerah yang jauh dari jalan raya. Hal ini menunjukkan bahwa pencemaran $\mathrm{Pb}$ umumnya berasal dari kendaraan-kendaraan bermotor. ( Fardiaz, 2006)

\section{Timbal di Udara}

Jumlah $\mathrm{Pb}$ di udara mengalami peningkatan yang sangat drastis sejak dimulainya revolusi industri di Benua Eropa. Asap yang berasal dari cerobongan pabrik sampai pada knalpot kendaraan telah melepaskan $\mathrm{Pb}$ ke udara. Hal ini berlangsung terus-menerus sepanjang hari, sehingga kandungan $\mathrm{Pb}$ di udara naik secara sangat mencolok sekali. Kenyataan ini secara dramatis dibuktikan dengan suatu hasil penelitian terhadap kandungan $\mathrm{Pb}$ yang terdapat pada lapisan es di Greenland pada tahun 1969.

Di samping itu, dalam bahan bakar kendaraan bermotor biasanya ditambahkan pula bahan scavenger, yaitu etilendibromida $\left(\mathrm{C}_{2} \mathrm{H}_{4} \mathrm{~B}_{2}\right)$ dan etilendikhlorida $\left(\mathrm{C}_{2} \mathrm{H}_{4} \mathrm{C}_{12}\right)$. Senyawa ini dapat mengikat residu $\mathrm{Pb}$ yang dihasilkan setelah pembakaran, sehingga di dalam gas buangan terdapat senyawa $\mathrm{Pb}$ dengan halogen.

Bahan aditif yang biasa dimasukkan ke dalam bahan bakar kendaraan bermotor pada umumnya terdiri dari $62 \%$ tetraetil-Pb. $18 \%$ etilendikhlorida. $18 \%$ etilendibromida dan sekitar $2 \%$ campuran tambahan dari bahan-bahan yang lain. Jumlah senyawa $\mathrm{Pb}$ yang jauh lebih besar dibandingkan dengan senyawa-senyawa lain dan tidak terbakar musnahnya $\mathrm{Pb}$ yang dibuang ke udara melalui asap buangan kendaraan menjadi sangat tinggi. Berdasarkan pada analisis yang pernah dilakukan dapat diketahui kandungan bermacam-macam senyawa $\mathrm{Pb}$ yang ada dalam asap kendaraan bermotor.

Senyawa tetrametil-Pb dan tetraetil-Pb dapat diserap oleh kulit. Hal ini disebabkan kedua senyawa tersebut dapat larut dalam minyak dan lemak. Sedangkan dalam lapisan udara tetraetil- $\mathrm{Pb}$ terurai dengan cepat karena adanya sinar matahari. Tetraetil-Pb akan terurai membentuk trietil-Pb, dietil-Pb dan monoetil-Pb. Semua senyawa uraian dari tetraetil-Pb tersebut memiliki bau yang spesifik seperti bau bawang putih. sulit larut dalam minyak akan tetapi semua senyawa turunan ini dapat larut dengan baik dalam air. Senyawa-senyawa $\mathrm{Pb}$ dalam keadaan kering dapat terdispersi di dalam udara, sehingga kemudian terhirup pada saat bernafas, dan sebagian akan menumpuk di kulit dan atau terserap oleh daun tumbuhan.

Sumber-sumber lain yang menyebabkan $\mathrm{Pb}$ dapat masuk ke udara ada bermacam-macam. Di antara sumber alternatif ini yang tergolong besar adalah pembakaran batu bara. asap dari pabrik-pabrik yang mengolah senyawa alkil-Pb, Pb-oksida. peleburan bijih dan transfer bahan bakar kendaraan bermotor. karena senyawa alkil-Pb yang terdapat dalam bahan bakar tersebut dengan sangat mudah menguap. ( Palar, 2008) 


\section{Pencemaran Logam Berat Dari Pupuk}

Pencemaran tanah didefinisikan sebagai peningkatan zat yang tidak diinginkan dalam tanah akibat aktivitas manusia yang telah menyebabkan kerusakan aktual maupun potensial terhadap mutu lingkungan. Logam berat merupakan komponen yang banyak terdapat di alam. Pencemaran logam berat dalam tanah terjadi jika konsentrasi logam berat sudah diatas batas ambang yang ditetapkan (Cottenie et al. 1982). Pemasuk logam berat dalam tanah pertanian antara lain bahan agrokimia (pupuk buatan dan pestisida), kendaraan bermotor, limbah industri dan pertambangan, serta logam berat yang berasal dari bahan induk pembentuk tanah tersebut. Pertanian organik yang terbebas dari penggunaan bahan-bahan kimia sintetis tidak serta merta juga terbebas dari pencemaran,

terutama logam berat. Bahan-bahan organik yang digunakan sebagai pupuk dapat menjadi sumber logam berat terutama timbal $(\mathrm{Pb})$ dan kadmium $(\mathrm{Cd})$ dalam tanah yang akan terserap oleh tanaman. Alloway (1990) menyatakan bahwa pupuk organik memiliki kandungan $\mathrm{Pb}$ dan Cd yang cukup tinggi. (Khatimah, 2006).

\section{N. Keracunan oleh Logam Timbal}

Keracunan yang ditimbulkan oleh persenyawaan logam $\mathrm{Pb}$ dapat terjadi karena masuknya persenyawaan logam tersebut ke dalam tubuh. Proses masuknya $\mathrm{Pb}$ ke dalam tubuh dapat melalui beberapa jalur, yaitu melalui makanan dan minuman, udara dan perembesan atau penetrasi pada selaput atau lapisan kulit.

Sebagian besar dari $\mathrm{Pb}$ yang terhirup pada saat bernafas akan masuk ke dalam pembuluh darah paru-paru. Tingkat penyerapan itu sangat dipengaruhi oleh ukuran partikel dari senyawa $\mathrm{Pb}$ yang ada dan volume udara yang mampu dihirup pada saat peristiwa bernafas berlangsung. Makin kecil ukuran partikel debu, serta makin besarnya volume udara yang mampu terhirup maka akan semakin besar pula konsentrasi $\mathrm{Pb}$ yang diserap oleh tubuh. Logam $\mathrm{Pb}$ yang masuk ke paru-paru melalui peristiwa pernafasan akan terserap dan berikatan dengan darah paru-paru untuk kemudian diedarkan ke seluruh jaringan dan organ tubuh. Lebih dari 90\% logam $\mathrm{Pb}$ yang terserap oleh darah berikatan dengan sel-sel darah merah (erytrocyt).

Senyawa $\mathrm{Pb}$ yang masuk kedalam tubuh melalui makanan dan minuman akan diikutkan dalam proses metabolisme tubuh. Namun demikian jumlah $\mathrm{Pb}$ yang masuk bersama makanan dan atau minuman ini masih mungkin ditolerir oleh lambung disebabkan asam lambung (HCL) mempunyai kemampuan untuk menyerap logam $\mathrm{Pb}$. Tetapi walaupun asam lambung mempunyai kemampuan untuk menyerap keberadaan logam $\mathrm{Pb}$ ini. Pada kenyataannya $\mathrm{Pb}$ lebih banyak dikeluarkan oleh tinja.

Pada jaringan dan organ tubuh, logam $\mathrm{Pb}$ akan terakumulasi pada tulang, karena logam ini dalam bentuk ion $\left(\mathrm{Pb}^{2+}\right)$ mampu menggantikan keberadaan ion $\mathrm{Ca}^{2+}$ (kalsium) yang terdapat dalam jaringan tulang. Di samping itu, pada wanita hamil logam $\mathrm{Pb}$ dapat melewati plasenta dan kemudian akan ikut masuk dalam sistem peredaran darah janin dan selanjutnya setelah bayi lahir, Pb akan dikeluarkan bersama air susu.
Senyawa seperti tetraetil-Pb, dapat menyebabkan keracunan akut pada sistem syaraf pusat, meskipun proses keracunan tersebut terjadi dalam waktu yang cukup panjang dengan kecepatan penyerapan yang kecil.

Pada pengamatan yang dilakukan terhadap para pekerja yang bekerja menangani senyawa $\mathrm{Pb}$, tidak ditemukan keracunan kronis yang berat. Gejala keracunan kronis ringan yang ditemukan berupa insomnia dan beberapa macam gangguan tidur lainnya. Sedangkan gejala pada kasus keracunan akut ringan adalah menurunnya tekanan darah dan berat badan. Keracunan akut yang cukup berat dapat mengakibatkan koma dan bahkan kematian.

Meskipun jumlah $\mathrm{Pb}$ yang diserap oleh tubuh hanya sedikit. logam ini ternyata menjadi sangat berbahaya. Hal itu disebabkan senyawa-senyawa $\mathrm{Pb}$ dapat memberikan efek racun terhadap banyak fungsi organ yang terdapat dalam tubuh.

\section{O. Efek Timbal Terhadap Sistem Urinaria}

Senyawa-senyawa $\mathrm{Pb}$ yang terlarut dalam darah akan dibawa oleh darah ke seluruh sistem tubuh. Pada peredaranya, darah akan terus masuk ke glomerolus yang merupakan bagian dari ginjal. Dalam glomerolus tersebut terjadi proses pemisahan akhir dari semua bahan yang dibawa darah, apakah masih berguna bagi tubuh atau harus dibuang karena sudah tidak diperlukan lagi. Ikut sertanya $\mathrm{Pb}$ yang terlarut dalam darah ke sistem urinaria (ginjal) dapat mengakibatkan terjadinya kerusakan pada saluran ginjal. Kerusakan yang terjadi tersebut disebabkan terbentuknya intranuclear inclusion bodies yang disertai dengan membentuk aminociduria, yaitu terjadinya kelebihan asam amino dala urine. ( Palar, 2008)

\section{P. Penanggulangan Keracunan Timbal \\ - Pertolongan pertama}

Jika menemukan gejala-gejala keracunan timbal, masyarakat dapat memberi pertolongan pertama untuk sedapat mungkin menekan risiko dan dampaknya pada penderita. Untuk keracunan akut melalui saluran pencernaan misalnya, pasien sebaiknya segera dipindahkan agar tidak terpapar lagi dengan timbal. Bilas mulutnya dan berikan rangsangan untuk muntah ( untuk penderita yang sadar). Rujuklah segera ke bagian perawatan medis. Kasuskasus keracunan kronis dapat ditekan dengan berbagai cara dengan merujuk factor-faktor yang memungkinkan terjadinya keracunan tersebut. Misalnya, mengurangi kadar timbal dalam bensin untuk mengurangi pemaparan timbal melalui pernafasan. Dengan demikian dapat diharapkan terjadi penurunan kadar timbal dalam darah manusia. Keracunan yang biasa terjadi karena tumpahan timbal di lingkungan industri - industri besar dapat dihindari dengan membersihkan tumpahan dengan hati-hati ( untuk tumpahan sedikit), atau dilakukan secara landfills (untuk tumpahan yang banyak).

\section{Q. Upaya pencegahan}

Berbagai upaya dan tindakan pengamanan perlu dilakukan dalam rangka mencegah dan mengurangi pencemaran $\mathrm{Pb}$, baik yang berasal dari hasil pembakaran 
mesin mobil/motor maupun hasil industri atau dari makanan/minuman tercemar $\mathrm{Pb}$. (http://hexa.blogspot.com/2012/09/bahaya-timbal-bagikesehatan.html).

\section{R. Prinsip Dasar}

Selama bertahun-tahun detektor uap raksa mewakili penerapan analitis utama dari absorpsi atom. Tekanan uap raksa logam cukup besar sehingga membahayakan kesehatan dalam ruang yang ventilasinya tidak memadai. Detektor-detektor itu pada dasarnya adalah spektrofotometer primitive, dimana sumbernya adalah sebuah lampu uap raksa bertekanan rendah. Atom-atom raksa dieksitasi dalam dicas listrik lampu itu, memancarkan radiasi bila mereka kembali ke tingkatan elektronik yang lebih rendah, radiasi itubukan suatu kontinum ( tidak berkesinambungan ) melainkan terdiri dari frekuensi-frekuensi diskrit yang menyatakan transisi elektronik dalam atom raksa, dengan suatu garis yang istimewa kuatnya pada 253,7 nm yang berpadanan dengan selisih energi antara keadaan eksitasi pertama untuk Hg. (Day R.A, dkk,2002)

\section{U. Defenisi Operasional (DO)}

1.Timbal

Timbal adalah salah satu bahan pencemar utama saat ini dilingkungan. Hal ini bisa terjadi karena sumber utama pencemaran timbal adalah dari emisi gas buangan kendaraan bermotor.

2. Kubis

Kubis adalah tanaman yang termasuk dalam famili Cruciferae dan mempunyai nama latin Brassica oleracea. Tanaman ini merupakan salah satu jenis tanaman sayur yang umum diusahakan oleh para petani Indonesia

3. Efek samping

Senyawa seperti tetraetil-Pb, dapat menyebabkan keracunan akut pada sistem syaraf pusat, meskipun proses keracunan tersebut terjadi dalam waktu yang cukup panjang dengan kecepatan penyerapan yang kecil.gejala keracunan kronis ringan yang ditemukan berupa insomnia dan beberapa macam gangguan tidur lainnya. Sedangkangejala pada kasus keracunan akut ringan adalah menurunnya tekanan darah dan berat badan. Keracunan akut yang cukup berat dapat mengakibatkan koma dan bahkan kematian.

\section{Prosedur Kerja Sample}

Timbang sample sebanyak 1 gram. Masukkan kedalam cawan silika. Tambahkan 3 gr asam benzoat pada sample, Selanjutnya dipanaskan dalam furnance pada suhu $600{ }^{\circ} \mathrm{C}$ selama 6 jam sampai menjadi abu yang berwarna putih. Setelah itu abu dilarutkan dengan $5 \mathrm{ml} \mathrm{HNO}_{3}$ (p) sampai larut semua. Kemudian larutan diencerkan dengan akuadest. Kemudian dipanaskan di Hot plate, lalu dinginkan dan masukkan kedalam labu ukur. Setelah itu larutan diencerkan dengan aquadest sampai $100 \mathrm{ml}$. Baca hasil dengan menggunakan alat Spektrofotometer Serapan Atom pada panjang gelombang 248,3 nm. Larutan diinjeksikan pada alat Spektrofotometer Serapan Atom setelah alat dinolkan dengan pengaturan larutan blangko.
Pembacaa konsentrasi dilakukan 3x. (Baset, J, 1986 dalam Fitri Nurhayati).

\section{W.Perhitungan}

$$
\text { Konsentrasi } \mathrm{Pb}(\mathrm{mg} \%)=\left(\frac{a \times v}{w}\right) \times 100 \%
$$

a : Konsentrasi Sample (ppm)

b : Volume Pengenceran (ml)

$\mathrm{w}$ : Berat Sample (mg)

Contoh perhitungan sample No 2.

1. Sayur Kubis

Berat sample (w) : 1,1438 gr

Pembacaan $1\left(\mathrm{a}_{1}\right)$ : 0,0639 ppm

Volume (v) : $100 \mathrm{ml}$

$$
\begin{aligned}
& \text { Konsentrasi Pb (mg \%) } \\
= & \left(\frac{a \times v}{W}\right) \times 100 \% \\
= & \left(\frac{0,0639 \times 100}{1,1438 \times 1000}\right) \times 100 \% \\
= & \left(\frac{0,0639 \times 0,1}{1,1438}\right) \times 100 \% \\
= & 0,55 \mathrm{mg} \%
\end{aligned}
$$

\section{PEMBAHASAN}

Dari hasil penelitian yang dilakukan terhadap kadar timbal $(\mathrm{Pb})$ pada 5 sampel sayur kubis diperoleh hasil yang hampir sama yaitu pada sampel 1,3,4,5 dengan Kadar Timbal sekitar 0,25 mg\% - 0,32 mg\% dan hasil yang tertinggi terdapat pada sampel nomor 2 dengan Kadar $0,55 \mathrm{mg} \%$.

Hasil yang berbeda pada Sayur Kubis yang tertinggi yaitu dengan kadar 0,55 mg\%, karena pada sayur tersebut yang banyak terdapat mengandung Kadar Timbal yaitu pada asap kendaraan, terjadi karena penanaman yang terlalu dekat ke pinggir jalan. Pencemaran logam berat terjadi selama proses prapanen yaitu selama penanaman dan pemeliharaan, juga disebabkan pemakaian pupuk mikro yang mengandung tembaga. (Suismono, Miskiyah, Widraningrum, 2007)

Kontaminasi makanan juga bisa terjadi dari tanaman pangan (bidang pertanian) yang diberi pupuk dan pestisida yang mengandung logam. (Agustina Titin, 2007) Dari Tabel tersebut tersebut menunjukkan perbedaan kadar timbal yang besar dengan kata lain kadarnya hampir mendekati pada sampel 1,3 - 5 dan yang tertinggi mencapai 0,55 mg\%.

\section{KESIMPULAN}

Dari hasil penelitian yang dilakukan terhadap 5 sampel sayur kubis diperoleh hasil Kadar Pb yang berbeda pada kelima sayur kubis. Pada sayur kubis diperoleh Kadar $0,25 \mathrm{mg} \%$ - 0,55 mg\%.

\section{SARAN}

1. Dianjurkan kepada para konsumen agar sayuran dicuci bersih atau direndam 2 sampai 3 kali sebelum dimasak. 
2. Disarankan juga kepada masyarakat Tanah Karo Berastagi agar tidak menanam sayuran dekat dipinggir jalan atau dengan menggunakan pagar seng pada tanaman.

3. Disarankan juga untuk tindakan yang lebih bijak lagi adalah mengurangi pencemaran Timbal di lingkungan antara lain menggunakan bensin tanpa Timbal, Sehingga emisi Timbal ke udara berkurang.

4. Bagi pemerintah khususnya Dinas Pertanian hendaknya secara proaktif memberikan penyuluhan tentang sumber-sumber Timbal dan dampaknya terhadap kesehatan.

5. Kepada peneliti yang akan datang agar meneliti logam beracun lain yang ada pada sayur kubis tersebut sehingga dapat menjadi suatu informasi bagi masyarakat

\section{DAFTAR PUSTAKA}

Duryatmo Sardi, 2006, "Seri Mengenal Sayur Disekitar Kita, Cetakan Pertama”, PT Penebar Swadaya,Jakarta.

Fardiaz Srikandi, 2006, "Polusi Air Dan Udara”, Penerbit Kanisius, Universitas Pangan dan Gizi Institut Pertanian Bogor, Jl. Cempaka 9, Deresan, Yongyakarta.

Lu C Frank, 2002, "Toksikologi Dasar Asas Organ Sasaran Dan Penilaian Risiko”, Penerbit Universitas Indonesia (UI-PRESS), Jakarta.

Naria Evi, 2005, "Mewaspadai Dampak Bahan Pencemar Timbal (Pb) Dilingkungan Terhadap Kesehatan”, Jurnal Komunikasi Penelitian, Universitas Sumatera Utara.

Palar Heryando, 2008, "Pencemaran \& Toksikologi Logam Berat Cetakan ke-empat”, Penerbit Rineka Cipta, Anggota IKAPI, Jakarta.

Pracaya, 2000, “Kol Alias Kubis, Penerbit PT. Penebar Swadaya, Jl. Gunung Sahari III/7 Jakarta.
Rukmana, 2002, “Bertanam Kubis, Cetakan ke-2”, Penerbit Kanisius Jl. Cempaka 9 Deresan, Yongyakarta.

Siswandi, 2006, "Budidaya Tanaman Sayuran Cetakan Pertama”, PT Citra Aji Parama, anggota IKAPI No.043/DIY/03, Jl. Laksada Adisucipto 29, Yogyakarta.

S.P.Tafajani S. Dudy, 2011, "Panduan Komplit Bertanam Sayur Dan Buah-buahan, Cetakan Pertama”, Penerbit Universitas Atma Jaya Jl. Moses Gatotkaca No. 28, Yogyakarta.

Tombe Mesak \& Sipayung Hendra, 2010, "Bertani Organik Dengan Teknologi Biofob”, Penerbit Lily Publisher, Yongyakarta.

Day, R.A dan A. L. Underwood, 2002.” Analisis Kimia Kuantitatif”, Edisi Keenam. Jakarta : Erlangga.

Baset, J., et al, 1986, Vogel Text Book Of Quantitative In Organic Chemistry, 4-th edition, Long Man, London, 810, 835 - 837.

Suismono, Miskiyah dan Widraningrum, 2007.” Bahaya Kontaminasi Logam Berat Dalam Sayuran dan Alternatif Pencegahan Cemarannya.

Agustina Titin, Jurnal 2007.” Kontaminasi Logam Berat Pada Makanan dan Dampaknya Pada Kesehatan, Fakultas Tekhnik, UNNES.

Khatimah, 2006. "Perubahan Konsentrasi Timbal dan Kadmium Akibat Perlakuan Pupuk Organik Dalam Sistem Budi Daya Sayuran Organik “. Institut Pertanian Bogor.

(http://hex-a.blogspot.com/2012/09/bahaya-timbal-bagikesehatan.html)

(http:// Hildan Rosalina.blogspot.com/2012/08/Spektrofotometer Serapan Atom)

(http://anekaplanta.wordpress.com/2010/01/25/kebunsayur-di-pinggir-jalan- berbahaya) 